NASA Technical Memorandum 110414

\title{
Turbulence Modeling - Progress and Future Outlook
}

Joseph G. Marvin and George P. Huang

August 1996

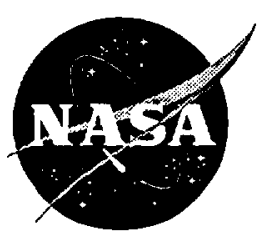

National Aeronautics and

Space Administration 
NASA Technical Memorandum 110414

\section{Turbulence Modeling - Progress and Future Outlook}

Joseph G. Marvin, Ames Research Center, Moffett Field, California George P. Huang, MCAT Inc., San Jose, California

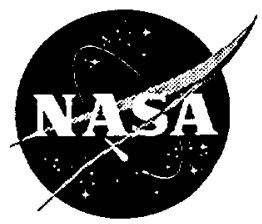

National Aeronautics and

Space Administration

\section{Ames Research Center}

Moffett Field, California 94035-1000 



\title{
TURBULENCE MODELING - PROGRESS AND FUTURE OUTLOOK
}

\author{
Joseph G. Marvin and George P. Huang*
}

Ames Research Center

\section{SUMMARY}

Progress in the development of the hierarchy of turbulence models for Reynolds-averaged NavierStokes codes used in aerodynamic applications is reviewed. Steady progress is demonstrated, but transfer of the modeling technology has not kept pace with the development and demands of the computational fluid dynamics (CFD) tools. An examination of the process of model development leads to recommendations for a mid-course correction involving close coordination between modelers, CFD developers, and application engineers. In instances where the old process is changed and cooperation enhanced, timely transfer is realized. A turbulence modeling information data base is proposed to refine the process and open it to greater participation among modeling and CFD practitioners.

\section{INTRODUCTION}

Despite the significant advances of computational fluid dynamics (CFD), turbulence modeling is still critical to its success for aerodynamic applications. New aircraft performance requirements are pushing the envelope of our experience and "time to market" considerations are requiring more sophisticated CFD early in the design cycle. A successful CFD tool would enhance our understanding of the effects of viscous, high Reynolds number flows associated with the design of these aircraft. The three-dimensional (3-D) time-dependent solution of the Navier-Stokes equations could provide an exact description of the turbulent motion, but the range of time and length scales associated with turbulence are such that they cannot be resolved when computing complex aerodynamic flows. As a consequence, the Reynolds averaged form of the Navier-Stokes equations together with a turbulence

"MCAT Inc., San Jose, California. model are the most practical means today of computing complex aerodynamic flows. Industry has started to use Reynolds-averaged Navier-Stokes (RANS) codes in their design cycle, even though the physical modeling is less than satisfactory.

There is no doubt significant progress in the field of turbulence modeling has been made. However, in contrast to the revolutionary pace of CFD development, turbulence modeling development has been evolutionary and the resulting pace of improvement has frustrated the CFD community. Some of the factors leading to the frustration are: the number of modeling research and development studies has proliferated over the last decade, yet no clear choice for suitable models seems to be emerging; the test cases used to validate turbulence models are only weakly relevant to "real" aerodynamic flow applications; reported successes are fragmentary or inconsistent and numerical aspects and their impact on efficiency are rarely discussed; and, there is a general lack of a systematic effort to transfer "successful" models to CFD application codes.

The latter point is a crucial aspect too often ignored and results in CFD applications being performed with models that fail to represent the best available alternative. Modeling and CFD development typically proceed on independent paths. CFD developers are expected to pick models from a myriad of choices, and, there is general lack of feedback between the groups on modeling successes and failures. It is absolutely necessary to rectify the situation because the likelihood of having a single code with a single turbulence model that can solve the breadth of CFD applications encountered in aerodynamics is remote. A viable systematic effort requires attention to the complete model development process and close collaboration among the two disciplines.

In this paper, progress in modeling is described first. Next, the process of model development is examined to provide insight into the reasons for the perceived slow pace of progress. Ideas for a mid-course correction in the process that could lead to a more satisfactory pace are proposed and discussed. Examples 
are given throughout to provide foundation to the ideas being advocated.

\section{PROGRESS}

\subsection{Background}

The formalism used to derive the RANS equations leads to the well known closure problem wherein the fluid motion is described by its mean and suitably averaged fluctuating motion. The latter is accomplished through turbulence modeling. A review of early progress in modeling provides an informative prelude to our discussion on the current status.

In 1968, the AFOSR-IFP Stanford Conference (ref. 1) was held to determine whether emerging numerical techniques together with a turbulence model were sufficient to solve spatially developing boundary layers. Finite difference numerical procedures were judged to provide suitable means for solving the boundary layer form of the RANS equations. The majority of comparisons with data were accomplished with incompressible codes using eddy viscosity models. No single modeling approach emerged as superior, but the potential of using RANS codes was demonstrated.

In 1969 (ref. 2) and 1972 (ref. 3) NASA conferences were held to assess early modeling progress on compressible boundary layers and shear layers. The available models, most of which were eddy-viscosity types and corrected for compressibility through Morkovin's hypothesis, were generally successful for boundary layers, but failed in some specific instances such as incompressible reattaching shear layers and growth rate predictions of compressible shear layers. Suggestions for further study were prevalent throughout the discussions, but optimism for expected improvements prevailed and follow-on research intensified.

During the next decade, considerable effort was undertaken to improve turbulence models and broaden the range of applications. Spurred by the arrival of the supercomputer, the effort focused on the closure problem. In particular, the development of two-equation and higher order Reynolds stress transport closure models pioneered by Launder and his colleagues offered the hope for accurate predictions of complex turbulent flows and perhaps the development of a universal model.
The 1980-1981 AFOSR-HTTM-Stanford Conference (ref. 4) was organized to assess general progress in modeling complex turbulent flows during the decade of the '70s. The conclusions that emerged from the conference evaluation committee were mixed. On the one hand, it was concluded that complex flows (still simple compared to those associated with aeronautical applications), including separated flows, could indeed be calculated with the more sophisticated numerical methods and models. On the other hand, the accuracy of the computations and the performance of the higher order Reynolds-stress models was disappointing. Including more physics did not necessarily lead to more accurate results and there was concern that computational errors (e.g., numerical convergence and grid resolution) affected the resulting conclusions. It was also apparent that the search for a universal model was not realized.

After a decade, Bradshaw, Launder, and Lumley initiated a sequel to the $1980-81$ conference. Their purpose was to assess subsequent progress in RANS model developments for complex flows during the intervening years. They developed and provided a modified, narrower scope evaluation data base, and required contributors to provide the results, either by postmail or electronic mail. The format was interactive and allowed modelers to see their comparisons relative to others and make adjustments if they thought they could improve their own predictions.

Bradshaw et al. (ref. 5) presented their conclusions on modeling progress with the aid of a single figure. The conclusions that emerged from their study were disappointing in light of the latitude provided to the contributors. Figure 1, taken from their report, shows the skin friction coefficient on a flat plate at momentum-thickness Reynolds number of 10,000 plotted against $I_{100}$, the value of $U / u_{\tau}$ at $u_{\tau} y / \nu=100$. The known value from experiment is depicted by the large "plus" symbol, which covers the range of experimental scatter. The other symbols represent various contributors' predictions and they scatter dramatically about a mean curve fit through them. They do not reproduce the experimental results. The flagged symbols are values predicted using the standard $k-\epsilon$ model, some with wall functions and some with integration to the wall. They do not agree with one another and show that different numerical schemes can lead to scatter in predictions even for the same model. Bradshaw et al. surmised that physical modeling progress was extremely difficult to evaluate in the absence of any 
consistent numerical assessment procedure even for the supposedly "universal" viscous wall region.

It is becoming clearer as more and more code assessment studies are conducted that errors are not attributable to modeling deficiencies alone. For example, at the recent workshop on CFD code assessment for turbomachinery (ref. 6), it was concluded that model deficiencies, numerical code errors and lack of training in the use of CFD codes were all factors contributing to differences between numerical solutions and their subsequent differences with data. The organizers also concluded that a single test case, although relevant to a practical flow, was probably too complicated to assess the accuracy of various turbulence models.

\subsection{Current Status}

The status of various modeling closures will be discussed in the order to which the Reynolds stresses are approximated.

The Reynolds stress transport models solve the transport equation for Reynolds stresses, $\overline{u_{i} u_{j}}$ directly:

$$
\frac{D \overline{u_{i} u_{j}}}{D t}=d_{i j}+P_{i j}+\phi_{i j}-\epsilon_{i j}
$$

The first term in the L.H.S. and the second term in the R.H.S. are convection and production terms, respectively, and require no modeling; the first term in the R.H.S. is the diffusion term and is in general modeled by a gradient diffusion approximation; the third term in the R.H.S. is the pressure-strain correlation. A majority of the modeling efforts have focused on this term. The last term is the dissipation term which is in general related to the scalar dissipation rate, governed by a transport equation. This type of model requires seven equations, in addition to the mean flow equations. Currently, there are a least four major variants being developed: Launder et al. (ref. 7), Shih and Lumley (ref. 8), Fu et al. (ref. 9) and Speziale et al. (ref. 10). The main difference between these variants is the pressure strain correlation modeling. For a detailed review of these models, see references 11-15. These models are just beginning to be evaluated for application to aerodynamic flows.

The Reynolds stress closure can be simplified by introducing a stress-strain relationship:

$$
\overline{u_{i} u_{j}}=-2 \nu_{t}\left(S_{i j}+\text { H.O.T. }\right)+\frac{2}{3} \delta_{i j} k
$$

where $S_{i j}=1 / 2\left(\partial U_{i} / \partial x_{j}+\partial U_{j} / \partial x_{i}\right), \nu_{t}$ is a turbulent eddy viscosity and the higher order terms (H.O.T.) contain nonlinear products of the strain and vorticity tensors, $S_{i j}$ and $\Omega_{i j}=1 / 2\left(\partial U_{i} / \partial x_{j}-\partial U_{j} / \partial x_{i}\right)$, respectively. The concept of including the high order terms in the stress-strain relationship was introduced in 1975 by Pope (ref. 16), who used the algebraic stress assumption of Rodi (ref. 17) to derive an explicit form for the higher order terms. Currently, there are at least three variants for this type of model: Gatski and Speziale (ref. 18), Shih et al. (ref. 19) and Craft et al. (ref. 20). In all these models, the turbulent eddy viscosity, $\nu_{t}$, is related to the turbulent kinetic energy, $k$ and its dissipation rate, $\epsilon$, by

$$
\nu_{t}=c_{\mu}\left(S^{*}, \Omega^{*}\right) \frac{k^{2}}{\epsilon}
$$

where $S^{*}$ and $\Omega^{*}$ are the dimensionless strain and vorticity invariants, $S^{*}=\sqrt{2 S_{i j}^{2}} k / \epsilon$ and $\Omega^{*}=$ $\sqrt{2 \Omega_{i j}^{2}} k / \epsilon$, respectively, and the values of $k$ and $\epsilon$ are obtained from their corresponding modeled transport equations.

Menter (ref. 21) observed that the ratio of production to dissipation of turbulent kinetic energy can be significantly larger than one in adverse pressure gradient flows. Under such conditions, employing a constant value of $c_{\mu}(\approx 0.09)$ leads to over-prediction of the turbulent shear stress. To remedy this problem, he proposed a modification to the eddy viscosity when the ratio of production and dissipation becomes large. His model provides significant improvement in predicting adverse pressure gradient flows, separated flows, and transonic shock separated flows (see fig. 2).

Interestingly, his modification, although intuitive and tested for linear eddy viscosity models, is in accord with (3), proposed for the nonlinear models. Figure 3 shows the variation of $c_{\mu}$ with $S^{*}$ compared with his. All models show a decrease in $c_{\mu}$ at high $S^{*}$ values corresponding to those for adverse pressure gradient and separated flows. Based on this observation, it is believed that the nonlinear models now under development will provide similar improvements. See for example references 22 and 23.

The majority of models employed in practical applications are linear eddy viscosity models. The value of eddy viscosity can be obtained by a family of two equation models, namely, $k^{m} \epsilon^{n}-k^{p} \epsilon^{q}$ models. For example, if one picks $m=1 / 2, n=0, p=-1$ and $q=1$, one arrives at the $q-\omega$ model. In theory, one form of the model can be transformed exactly into another form. Investigators have made refinements that lead to a wide variety of formulations. Among these, 
the most frequently used are: the $q-\omega$ model (ref. 24), the $k-\epsilon$ model (ref. 25), the $k-\omega$ model (ref. 26), the $k-l$ model (ref. 27), the $k-\tau$ model (ref. 28), and the SST model (ref. 21). The latter is a blend of the $k-\epsilon$ model in the outer region and the $k-\omega$ model in the near wall region. As mentioned above, it limits the ratio of production to dissipation. Results of computations with some of these models will be provided later.

In order to enhance numerical robustness and efficiency, Baldwin and Barth (ref. 29) proposed a single transport equation for $\nu_{t}$. Spalart and Allmaras (ref. 30) proposed an improved version of a $\nu_{t}$ model and results using this model will be shown subsequently. Other variants of $\nu_{t}$ models were derived earlier. See for example reference 31.

The most primitive form of eddy viscosity models is formed by relating its value directly to the mean velocity. These algebraic models are often employed in applications because they are numerically robust. The most often used models are: the Baldwin-Lomax (ref. 32) and the Cebeci-Smith (ref. 33) models. Johnson and King (ref. 34) improved the physical modeling for adverse pressure gradient and transonic flow applications by introducing an additional O.D.E. that accounts for turbulence history effects. The modification greatly improved predictions of transonic wing performance (ref. 35). An example (ref. 36) showing calculations with this model of the flow field and pressures for a 747 wing-body combination is shown in figure 4.

Several alternatives are available for modeling in the vicinity of solid surfaces: 1) the use of wall functions; 2) switching to a one-equation or a two-equation model near the wall; and 3) integrating the model equations to the wall. The wall function techniques make use of the law of the wall. The region between the first grid point and the wall is divided into a single (ref. 37) or several zones (refs. 38 and 39). For compressible flows, the van Driest law of the the wall formally and correctly extends the wall functions to compressible flows (refs. 40 and 41 ). The use of oneequation (refs. 42-45) (or two-equation (ref. 46)) models in the sublayer allows the transport of turbulent energy to be accounted for. Despite success with the latter approach many modelers prefer to use low Reynolds number damping that allows direct integration of the governing equations down to the wall. For a description of the more commonly applied methods used with two-equation models see: the $q-\omega$ model of Coakley (ref. 24); the $k-\epsilon$ models of Launder and Sharma (ref. 25), Chien (ref. 47) and Lien and Leschziner (ref. 48); the $k-\omega$ model of Wilcox (ref. 26); and the SST model of Menter (ref. 21). The $k-\epsilon-\overline{v^{2}}$ model of Durbin (ref. 49 and 50) allows direct integration to the wall without recourse to a damping function by introducing an additional $\overline{v^{2}}$-equation, as does the Wilcox $k-\omega$ model.

The development of near wall modeling for Reynolds stress transport equations is still evolving (refs. 51-56). Demonstration applications of these models are still limited to simple boundary layer flows.

Favre averaging is the most common technique for extending incompressible models into the compressible flow regime. A comprehensive investigation of the differences between Favre and Reynolds averaging may be found in Huang et al. (ref. 57). Generally, in addition to the compressible mean dilatation terms, additional terms such as the dilatationdissipation and pressure-dilatation fluctuation terms arise and require modeling. Zeman et al. (ref. 58) and Sarkar et al. (ref. 59) independently proposed that dilatation-dissipation augments the solenoidal dissipation by a function of $M_{t}^{2}$, where $M_{t}$ is the turbulent Mach number. Their models have been applied to compressible mixing layers and successfully predict the decrease in shear layer spreading at high Mach numbers (ref. 60). Models for the pressure-dilatational fluctuation correlation have also been proposed (refs. 61-63). These models were also focused on predictions of simple sheared mixing layers. Recent work by Huang et al. (refs. 57 and 64) suggests, however, that both of these models for dilatational-dissipation and the pressuredilatation fluctuation correlations may not be useful for near-wall flows. Indeed, experience has shown that for prediction of subsonic and supersonic flows these two modifications degrade the results and are not recommended.

For the prediction of hypersonic near-wall flows, Coakley and Huang (refs. 65 and 66) proposed two modifications for current two-equation eddy viscosity models: one compression modification to cure the under-prediction of separation bubble size caused by shock wave/boundary layer interactions; and the other, a length scale modification to remedy the overprediction of heat transfer rate near re-attachment points. These two modifications have been validated for a range of hypersonic flows. The modifications are formulated in a general manner so they can be applied in any existing two-equation model formulation. An 
example illustrating the effects of these modifications on the prediction of the hypersonic flow over a cylinder flare is shown in figure 5 .

\section{PROCESS OF MODEL DEVELOPMENT}

In the Spring of 1994, a NASA Turbulence Modeling Standards Committee was formed to undertake an independent evaluation of the process of turbulence model development and suggest changes that could enhance the quality of models used in CFD application codes. The Committee membership, comprised of experts from NASA, Industry and Academia, is listed in the Acknowledgment section.

The Committee established a set of turbulence modeling evaluation criteria or standards that turbulence modelers would be encouraged to apply. These criteria would enable CFD'ers to make intelligent choices for models to incorporate into their application code. In addition, they would provide modelers (and the aeronautical community at large) with relevant comparative metrics to assess progress on new or improved model development and to identify modeling shortcomings.

Four critical elements of the process where change is necessary will be discussed here. The first involves numerical procedures. The second involves the selection and use of standard validation data bases as a means of assessing model performance. The third involves establishing standard numerical solutions to insure accurate implementation of models into application codes. The fourth involves the development of a mechanism for insuring that "successful" models get transported into application codes. This element is the most challenging and important part of the total process. It requires renewed cooperation among modelers and code developers.

\subsection{Numerical Procedures}

Integration of the conservation and accompanying modeling equations requires careful consideration of errors resulting from the numerical procedures. As discussed above, inattention to such procedures clouds the interpretation of a turbulence model's performance.
Various alternative methods for implementing models in RANS codes may lead to numerical stability problems. In most cases, instabilities are caused by improper treatment of source terms. Often this is construed as "bad" modeling physics. Therefore it is essential that the modelers fully describe their procedures for handling source terms. A detailed discussion of the successful numerical strategies for implementing various types of models and corresponding computational times is provided by Gatski (ref. 12). In addition, sensitivity of the solutions to the number of grid points, to boundary conditions (e.g., free-stream and inflow) and to $y^{+}$at the first grid point adjacent to the wall must be taken into consideration.

The following solutions for an incompressible plate flat flow illustrate how sensitivity studies should be conducted and they serve to explain some of the factors for the scatter of the results shown in figure 1. The following conditions were used in the calculations unless it is otherwise stated. The skin friction is reported at $R e_{\theta}=10,000$, where the solution is not affected by the inflow conditions. The ratio of turbulent viscosity to molecular viscosity in the freestream, $\mu_{t} / \mu_{l}$, and the ratio of the square root of the freestream turbulent kinetic energy to the freestream velocity, $\sqrt{k} / U_{\infty}$, were both taken to be 0.1 percent. The computational box was defined by $R e_{L}=2 \times 10^{7}$ (resulting in $R e_{\theta}$ up to $2.5 \times 10^{4}$ ) with a height to length ratio of 0.02 . The grid points were expanded exponentially from the wall to the top of the domain with an expansion ratio determined by the choice of the value of $y^{+}$at the first grid point. The value of $y^{+}$at the first grid point was kept approximately 0.1 . A detailed discussion is given in reference 67.

Grid sensitivity. Computations using the several popular turbulence models were performed with 50 , $100,250,500$, and 1000 grid points in the y direction. This corresponds to approximately $35,65,145$, 265 , and 465 grid points inside the boundary layer at $R e_{\theta}=10000$. The results, shown in figure 6 , are presented as the percent error with respect to the solution obtained using 1000 grid points. The zero- and one-equation models are less sensitive to the grid refinement. In general, errors can be controlled within less than 2 percent if 100 grid points are used in the calculations (corresponding to 60 grid points inside the boundary layer).

Sensitivity to $y^{+}$at the first grid point, $y_{1}^{+}$. Computations were performed with $y_{1}^{+} \approx 0.014,0.14$, 
$0.4,0.7,1.1$, and 1.4 using 500 points in the $y$ direction. The results, shown in figure 7 , are presented as the percent error with respect to the solution obtained using $y_{1}^{+} \approx 0.014$. The $k-\epsilon$ model is the most sensitive. In general, one should limit the value of $y_{1}^{+}$ to be less than 0.3 to have accurate solutions.

Freestream boundary condition sensitivity. Computations were performed by fixing the freestream value of $\sqrt{k} / U_{\infty}$ at 0.1 percent while varying the value of freestream turbulent viscosity to molecular viscosity ratio according to $\mu_{t} / \mu_{l}=10^{n}$. The values of $n$ were chosen to be $-6,-3,-1$, and 0 . Figure 8 shows the sensitivity as a percent of the value of the model solutions for $n=-6$. The $k-\omega$ model is very sensitive to freestream conditions. See Menter (ref. 68). In general, one should maintain the value of $n$ less than -3 (for the $k-\omega$ model).

Code invariant test. Three codes were used to establish a standard solution for the incompressible flat plate flow: a boundary layer code (ref. 69), an incompressible Navier-Stokes code (INS2D) (ref. 70) and a compressible Navier-Stokes code (ref. 71). The solutions for each code were established following the guidelines recommended above. Figure 9 shows the comparison of the results obtained by the three codes using Menter's SST model. Differences in the region $R e_{\theta}<5000$ were mainly due to the different inflow conditions used in the three solutions. Differences in skin friction coefficients are less than 1 percent after $R e_{\theta}>5000$. Comparisons using the other models show similar results. The solutions are essentially code independent and the results provide a standard numerical solution for each of the models.

\subsection{Standard Validation Data}

Turbulence modeling to a large extent is an empirical science. Models mimic the real physics and confidence is established by comparing modeled solutions against experiment or direct numerical simulations. Since direct numerical simulations are limited, comparisons with experiment provide the best measure of a model's performance for engineering applications.

The NASA Standards Committee deliberated extensively on the type of data base needed to facilitate interaction between modelers and CFD developers. They concluded that a standard data base should be developed. They recommended the small set of experimental test cases shown in table 1 as a first step in evaluating models for external aerodynamic flows. The choices were based on personal experience and knowledge about the data base and prior computations of them. The motivation was to rule out possibilities of including inferior data and unforeseen difficulties in specifying the boundary conditions. Furthermore, the flows were considered challenging enough to sort out modeling differences and could comprise the metrics for assessing model improvement. The majority of the flows are two-dimensional (2-D), mainly because there is still a dearth of well defined 3-D experiments.

\subsection{Standard Solutions}

Standard solutions for a number of the test cases employing several turbulence models have been established by researchers at the Ames Research Center

Table 1. Recommended test cases for external aerodynamic flows

\begin{tabular}{|c|c|c|c|}
\hline & Subsonic incompressible & Transonic & Supersonic \\
\hline $\begin{array}{l}\text { Priority } \\
\text { cases }\end{array}$ & $\begin{array}{l}\text { Flat plate } \\
\text { APG boundary layer (ref. } 72 \text { ) } \\
\text { Self similar mixing layer } \\
\text { Self similar round jet } \\
\text { Self similar plane jet } \\
\text { Self similar plane wake } \\
\text { Infinite yawed wing (refs. } 73 \text { and } 74 \text { ]) }\end{array}$ & $\begin{array}{l}\text { Axisymmetric } \\
\text { bump (ref. 75) } \\
\text { RAE2822 airfoil } \\
\text { (ref. 76) }\end{array}$ & $\begin{array}{l}\text { Flat plate } M=5 \\
\text { Compressible } \\
\text { mixing layer } \\
\text { (ref. 77) }\end{array}$ \\
\hline $\begin{array}{l}\text { Optional } \\
\text { cases }\end{array}$ & $\begin{array}{l}\text { 3-D boundary layer in } \\
\text { transition duct (ref. } 78 \text { ) } \\
\text { Concave and convex } \\
\text { curvatures (ref. } 79 \text { and } 80 \text { ) } \\
\text { Backward-facing step (ref. } 81 \text { ) }\end{array}$ & MBB airfoil (ref. 82) & $\begin{array}{l}M=2.9 \\
\text { incipient } \\
\text { separation } \\
\text { (ref. 83) }\end{array}$ \\
\hline
\end{tabular}


(ref. 67). The group, Dr. T. J. Coakley, Dr. J. A. Bardina, and Dr. P .G. Huang, maintained the rigorous standards for numerical procedures discussed previously. In most cases several codes were used to insure, to as great a degree as possible, that numerical stability issues were eliminated. These benchmark solutions enable modelers and code developers alike to gauge model development progress. Moreover they provide code developers with a means to validate model implementation.

Four models were selected in their study: the Launder-Sharma $k-\epsilon$ model (ref. 25), the Wilcox $k-\omega$ model (ref. 26), the Spalart-Allmaras $\nu_{t}$ model (ref. 30) and the Menter SST model (ref. 21). Some example results follow.

Driver's adverse pressure gradient boundary layer. Figure 10 shows comparisons of the pressure and skin friction coefficients. With the exception of the $k-\epsilon$ model, all models predict flow separation. Overall the SST model provides the best solution.

Bachalo-Johnson axisymmetric bump. Figure 11 shows the comparison of the pressure coefficients along the surface of the axisymmetric bump. Both $k-\epsilon$ and $k-\omega$ models predict shock positions too far downstream as a result of underpredicting the size of the separation bubble. The SST and SpalartAllmaras models show better agreement.

Transonic airfoil - RAE2822. The comparison of the pressure and skin friction coefficients are shown in figure 12. Again, both the $k-\epsilon$ and $k-\omega$ models predict the shock position too far downstream. All the models overpredict the pressure recovery toward the trailing edge.

From these few examples it is apparent that a code developer would probably not want to use either the $k-\epsilon$ or $k-\omega$ models in transonic flow applications.

\subsection{Turbulence Modeling Technology Transfer}

The last critical element of the process is the transfer of technology from modelers to code developers and application engineers. Historically, this has been the weak link in the process. The left diagram in figure 13 depicts the flow of modeling technology for the typical development paradigm. The lower box and triangle represent the suite of test cases used to demonstrate model performance. The upper box and inverted triangle represent the more complex engineering applications. The gap between causes a delay in the transfer because of the uncertainty in knowledge of how models will perform in more complex applications and the numerical impact they might have on the performance of application codes.

A new paradigm, depicted in the diagram on the right, is needed. An overlap must be created to affect timely transfer. It requires close cooperation between modelers, code developers, and application engineers. For example, modelers will need to cooperate in extending evaluations to more complex flows and to adhere to the standards discussed above; code developers will need to participate to some degree in the evaluation by performing some of the test flows with their own codes to insure models have been implemented properly. Code developers and application engineers will need to work with modelers to break down their very complex applications conceptually into more manageable generic flow representations in order to create a broader modeling standard data base. Creating the overlap will also provide a better feedback mechanism on model performance in complex flows that can spur timely improvements.

Indeed, the pace at which "successful" models are implemented in application codes has accelerated in the few instances where this new paradigm is beginning. One such example was the formation of a Turbulence Modeling Integration Team at Ames Research Center whose focus was directed toward improving modeling for high lift applications using the INS-2D code. Menter (ref. 21) was instrumental in developing his own model and assessing its performance along with other models by using many of the standard test cases recommended above. It is noteworthy that he used the basic algorithm in the INS-2D code to develop his model and make his assessments. As a result, Rogers (ref. 84) was able to make use of all his work almost immediately by transferring the model subroutines to the full INS-2D code. Feedback on model performance was almost immediate. The first publication dates for Menter's model and Rogers' benchmark high lift computations were separated by only six months (compare this with the difference of several years in dates for the development and application of the Johnson-King model in the benchmark wing calculation shown in fig. 4).

Additional information was collected during the preparation of this paper to further show the importance of the cooperative aspect of model development. 
Table 2. Turbulence models available in NASA CFD codes

\begin{tabular}{|c|c|c|c|c|}
\hline \multirow[t]{2}{*}{ Code } & \multicolumn{3}{|c|}{ Turbulence models available } & \multirow[t]{2}{*}{ Supporting modelers } \\
\hline & 0-equation & 1-equation & 2-equation & \\
\hline $\begin{array}{l}\text { NPARC } \\
\text { (Lewis) }\end{array}$ & $\begin{array}{l}\text { B-L } \\
\text { P.D.Thomas } \\
\text { Ahn's RNG }\end{array}$ & $\begin{array}{l}\text { B-B } \\
\text { S-A }\end{array}$ & $\begin{array}{l}\text { Chien } k-\epsilon \\
\text { Shih-Lumley } k-\epsilon \\
k-\omega\end{array}$ & $\begin{array}{l}\text { Shih, Yang, and Zhu (CMOTT) } \\
\text { Sirbaugh (NYMA) } \\
\text { Georgiadis (Lewis) }\end{array}$ \\
\hline $\begin{array}{l}\text { INS2D/3D } \\
\text { (Ames) }\end{array}$ & B-L & $\begin{array}{l}\text { B-B } \\
\text { S-A }\end{array}$ & SST & $\begin{array}{l}\text { Spalart(Boeing) } \\
\text { Menter(Eloret) } \\
\text { Rogers(Ames) }\end{array}$ \\
\hline $\begin{array}{l}\text { CFL3D } \\
\text { (Langley) }\end{array}$ & B-L & $\begin{array}{l}\text { B-B } \\
\text { S-A }\end{array}$ & $\begin{array}{l}k-\omega \\
\text { SST }\end{array}$ & $\begin{array}{l}\text { Johnson and Barth(Ames) } \\
\text { Menter(Eloret) } \\
\text { Gatski and Rumsey(Langley) } \\
\text { Abid(HTC) }\end{array}$ \\
\hline
\end{tabular}

In table 2, a list of turbulence models available in several NASA application codes is provided. As a baseline in all these codes, the Baldwin-Lomax model is available. What is interesting is that the best of the newly developed one- and two-equation models were incorporated with the assistance of modelers. Some examples of benchmark calculations using the these models are presented next.

The first example involves the calculation of a McDonnell-Douglas multi-element airfoil using INS-2D (ref. 84). The test data were the focus of a NASA CFD Challenge Workshop on high-lift hosted at NASA Langley. Lift curve variation with angle of attack to values near maximum lift were predicted quite well by the new models. Figure 14 shows a comparison of the calculations of pressure coefficient at a Reynolds number of 9 million and $21 \mathrm{deg}$ angle of attack using the two models that performed the best against the standard data base. Both the Spalart-Allmaras and SST models provide good predictions. The calculations are not as good at and beyond maximum lift and that information feedback is spurring work on model improvements.

Another example is the calculation of the flow over a military F/A-18 E/F wing section model (ref. 85). A major difference between the commercial and the military airfoils is that the military airfoil stalls at a markedly lower angle of attack $(\approx 3 \mathrm{deg})$ due to leading edge flow separation. Figure 15 shows a comparison of the calculations and experiment for the pressure coefficient at a Reynolds number of 16 million and 4 deg angle of attack. Again, calculations with the two models match the experimental data.
Benchmark calculations (ref. 86) of a transport wing mounted on a circular cross section fuselage, have been made with the NASA TLNS 3-D code (a derivative of CFL3D) as part of a code validation program. Figure 16 shows comparisons with the measured pressure coefficients at two spanwise locations. The calculations using the Spalart-Allmaras and SST models show better agreement in the shock region compared with those using the Baldwin-Lomax model. Better predictions of lift and moment coefficients are realized as a consequence.

\section{FUTURE OUTLOOK}

The evolution of turbulence modeling improvement requires substantial and synergistic interaction among CFD developers, modelers, and experimentalists. It was shown above that the pace of development could be accelerated through a coordinated effort. What needs to be done in the future is to expand the concept and open it to greater participation. An excellent vehicle for accomplishing this is to establish a turbulence model information system data base, accessible on the internet through the World Wide Web. The information system would provide streamlined access to the information needed to gage development of turbulence models, to correctly implement them into application codes and to provide feedback for initiating timely improvements.

Figure 17 presents a conceptual sketch of a possible information system. The inner shell is the heart. It 
would contain such information as model descriptions, numerical strategies, standard data bases, and standard numerical solutions showing comparisons with the data base. As a dynamic and evolving system it could be continually updated as developments warrant. The outer shell is comprised of CFD'ers, modelers, and experimentalists. Individually or in teams they would have streamlined access and coordination channels through the Web. For example, modeler's could access the standard benchmark test cases to measure their improvements; experimentalists could determine gaps in the data base and propose and perform additional experiments from a more informed perspective; and CFD developers and application engineers would have the opportunity to make informed choices of models and validate their implementation. Teams could be formed, formally or informally, as a means of accelerating development for specific applications. Geographical and organizational boundaries would not have to be considered but access to some of the information could be controlled, if necessary.

An oversight filter for the heart of the system would have to be provided in order to avoid proliferation of unchecked information. This could be accomplished by forming an oversight committee comprised of members from academia, industry and research laboratories. The committee could meet at regular intervals to evaluate progress, to discuss application needs, to concur on updating the experimental and numerical data bases, and to make informed assessments on the current state-of-the-art.

With such a system in place, the future prospects for providing timely, accurate RANS codes for engineering applications are promising.

\section{CONCLUDING REMARKS}

Turbulence modeling is critical to the development of accurate RANS CFD codes. Progress in model improvement has been evolutionary over the past few decades. It is now possible to predict pressure distributions in aerodynamic applications with confidence using mixing length eddy viscosity models so long as the pressure gradients are small and shock waves are weak because these models give correct viscous displacement effects. Skin friction and heat transfer can also be predicted to engineering accuracy's ( 5 percent), but attention must be given to grid refinement and free stream boundary condition influence on the model choice. The situation is quite different for applications involving strong pressure gradient, strong shock waves, and separation. When the flow is either subsonic or supersonic and any separation regions are small, eddy viscosity models, both mixing length and 1- and 2-equation models, can also provide adequate predictions of pressures because displacement effects are properly computed. Eddy viscosity models must be modified to properly account for shock location and attendant small separation for transonic flows before pressures can be predicted because the displacement effects which have a first order influence are not correct. The model of Johnson and King is an example of an improvement to mixing length models to handle this situation. No definitive conclusions regarding the ability to predict skin friction and heat transfer in these applications, or for that matter even pressures and separation extent for applications involving the strong interactions, can be given. Progress toward this end is being made by improving eddy viscosity models and moving toward higher-order model closures. Indeed, prospects are good. However, these improvements are not always recognized by the CFD developers, their pace appears too slow, and perhaps more importantly, their timely introduction into application codes is not being realized.

Four critical elements of the process for model development were examined in detail and systematic procedures were proposed to remedy the situation. The first involved insurance that adequate numerical procedures were followed to establish such things as source term stability, grid refinement, and free stream boundary condition requirements. The second involved the creation of a standard data base to provide benchmarks for assessing progress. The third involved the creation of standard numerical solutions to insure accurate utilization of models in application codes. The fourth involved following a systematic mechanism for transfer of "successful" models into the application codes. All of these elements require renewed cooperation between model and code developers. In a small number of instances where these procedures are followed, model improvements were implemented in application codes in a timely fashion. Moreover, the feedback from benchmark application computations has spurred modelers to search for new improvements.

In the future, these procedures need to be refined and opened to greater participation among the modeling research and application communities. A logical 
path to this end can be realized using a turbulence information system data base. The heart of the system would contain such information as model descriptions, numerical strategies for solving the model equations, standard data bases, and standard numerical solutions. It would be a "living" system with filtered, continuous updating. Access to the system could be easily developed over the internet through the World Wide Web. Such an approach holds great promise for the future prospects of turbulence modeling.

\section{ACKNOWLEDGMENT}

The authors wish to thank members of NASA Turbulence Modeling Standards Committee for their valuable inputs: T. J. Coakley (ARC), D. A. Driver (ARC), T. Gatski (LaRC), N. Mansour (ARC), R. Mankbadi (LeRC), S. K. Robinson (LaRC), T.-H. Shih (CMOTT-ICMOP, LeRC), R. Cosner (MDA-E), M. Sindir (Rocketdyne-Rockwell), B. Smith (Lockheed), P. Spalart (Boeing), P. Bradshaw (Stanford U.) and C. Speziale (Boston U.). We also wish to thank D. A. Johnson for pointing out that Menter's SST and the nonlinear eddy viscosity models can be usefully compared when plotting $c_{\mu}$ against $S^{*}$. Special thanks go to: Drs. S. E. Rogers, N. Georgiadis and C. L. Rumsey for providing us information on INS2D/3D, NPARC and CFL3D, respectively. Finally, we would like to thank Drs. T. J. Coakley, M. L. Merriam and Prof. P. Bradshaw for their comments and suggestions.

\section{REFERENCES}

1. Kline, S. J.; Markovin, M. V.; Sovran, G.; and Cockrell, D. J.: editors, Proceeding of Computation of Turbulent Boundary Layers - 1968 AFOSR-IFP-Stanford Conference, vols. 1 and 2, Thermoscience Division, Dept. of Mech. Engrg., Stanford University, 1969.

2. Bertram, M. H.: editor, Compressible Turbulent Boundary Layers, NASA SP-216, 1969.

3. Free Turbulent Shear Flows, vols. 1 and 2, NASA SP-321, 1973.
4. Kline, S. J.; Cantwell, B. J.; and Lilley, G. M.: editors, Proceeding of the 1980-1981 AFOSRHTTM-Stanford Conference on Complex Turbulent Flows: Comparison of Computation and Experiment, vol. 1-3, Thermoscience Division, Dept. of Mech. Engrg, Stanford University, 1981.

5. Bradshaw, P.; Launder B. E.; and Lumley, J. L.: JFE, in press, 1996.

6. Strazisar, A. J.; and Denton, J. D.: Global Gas Turbine News, IGTI, May/June, 1995, pp. 12-14.

7. Launder, B. E.; Reece, G. J.; and Rodi, W.: J. Fluid Mech., vol 68, part 3, 1975, pp. 537-566.

8. Shih, T.-H.; and Lumley, J. L.: Tech. Rep. FDA-85-3, Cornell University, 1985.

9. Fu, S.; Launder, B. E.; and Tselepidakis, D. P.: Rep TFD/87/5, Mech. Eng'rg Dept., UMIST, 1987.

10. Speziale, C. G.; Sarkar, S.; and Gatski, T. B.: J. Fluid Mech., vol. 227, pp. 245-272, 1991.

11. Speziale, C. G.: Chapter 5, in Simulation and Modeling of Turbulent Flow, ed., Gatski, T. B., Hussaini, M. Y. and Lumley, J. L, Oxford U. Press, 1996.

12. Gatski, T.: Chapter 6, in Handbook of Computational Fluid Mechanics, ed., R. Peyret, Academic Press Ltd, 1996.

13. Leschziner, M. A.: XXVI IAHR Congress "Hydra 200," London, Sept, 1995.

14. Shih, T.-H.: NASA CR-198458, 1996.

15. Bradshaw, P.: Engineering Foundation Conference on Turbulent Heat Transfer, San Diego, March 10-15, 1996.

16. Pope, S. B.: J. Fluid Mech., vol. 72, 1975, pp. 331-340.

17. Rodi, W.: Z. Angew. Math Mech., vol. 56, T219-T221, 1976.

18. Gatski, T. B.; and Speziale, C. G.: J. Fluid Mech., vol. 254,1993 , pp. 59-78.

19. Shih, T.-H.; Zhu, J.; and Lumley, J. L.: Comput. Methods Appl. Mech. Engrg, vol. 125, 1995, pp. 287-302.

20. Craft, T. J.; Launder, B. E.; and Suga, K: In Proc. 5th Int. Symp. on Refined Flow Modelling and Turbulence Measurements, p. 125, Presses Ponts et Chaussées, Paris, 1993. 
21. Menter, F. R.: AIAA J., vol. 32, no. 8, 1994, pp. 1598-1605.

22. Abid, R.; Rumsey, C.; and Gatski, T: AIAA J., vol. 33, no. 11, pp. 2026-2031, 1995.

23. Abid, R.; Rumsey, C.; and Gatski, T: AIAA 96-0565, 1996.

24. Coakley, T. J.: NASA TM-88333, 1986.

25. Launder, B. E.; and Sharma, B. I.: Letters in Heat and Mass Transfer, vol. 1, 1974, pp. 131-138.

26. Wilcox, D. C.: AIAA J., vol. 26, no. 11, 1988, pp. 1299-1310.

27. Smith, B. R.: AIAA-94-2386, 1994.

28. Speziale, C. G.; Abid, R.; and Anderson, E. C.: AIAA J., vol. 30, no. 2, 1992, pp 324-331.

29. Baldwin, B. S.; and Barth, T. J.: NASA TM-102847, 1990.

30. Spalart, P. R.; and Allmaras, S. R.: La Recherche Aèrospatiale, vol. 1, 1994, pp. 5-21.

31. Shur, M.; Strelets, M.; Zaikov, L.; Gulyaev, A.; Kozlov, V.; and Secundov, A.: AIAA 95-0863, 1995.

32. Baldwin, B. S.; and Lomax, H.: AIAA-78-257, 1978.

33. Cebeci, T.; and Smith, A. M. O.: Analysis of Turbulent Boundary Layer, Series in Appl. Math. and Mech., vol. XV, Academic Press, 1974.

34. Johnson, D. A.; and King, L. S.: AIAA J., vol. 23, no. 11,1985 , pp. $1684-1692$.

35. Johnson, D. A.: AIAA J., vol. 25, no. 2, 1987, pp. 252-259.

36. Yu, N.: AIAA-92-2651, 1992.

37. Launder, B. E.; and Spalding, D. B.: Comput. Methods in Appl. Mech. Eng., vol. 3, 1974, pp. 269-289.

38. Chieng, C. C.; and Launder, B. E.: Numerical Heat Transfer, vol. 3, 1980, pp. 189-207.

39. Johnson, R. W.; and Launder, B. E.: Numerical Heat Transfer, vol. 5, pp. 493-496.

40. Viegas, J. R.; and Rubesin, M. W.: AIAA 85-0180, 1985.

41. Huang, P. G.; and Coakley, T. J.: Engineering Turbulence Modeling and Experiments 2, W. Rodi and F. Martelli, editors, Elsevier Science Publishers B. V., 1993, pp. 731-739.

42. Iacovides, $\mathrm{H}$.; and Launder, B. E.: ASME 90-GT-24, ASME Int. Gas Turb. Congress, Brussels, 1990.

43. Rodi, W.: AIAA-91-0216, 1991.
44. Horstman, C. C.: AIAA J., vol. 30, no. 6, 1992, pp. 1480-1481.

45. Lien F. S.; and Leschziner, M. A.: The Aeronautical Journal, 99, 1995, pp. 125-144.

46. Abou Haidar, N. I.; Iacovides, $\mathrm{H}$.; and Launder, B. E.: in 77th Symp. of the Propulsion and Energetics Panel on CFD Techniques for Propulsion applications, San Antonio, Tex., 1991.

47. Chien, K. Y.: AIAA J., vol. 20, no. 1, 1982, pp. 33-38.

48. Lien F. S.; and Leschziner, M. A.: Engineering Turbulence Modeling and Experiments 2, W. Rodi and F. Martelli, editors, Elsevier Science Publishers B. V., 1993, pp. 217-228.

49. Durbin, P. A.: Theoretical and Computational Fluid Dynamics, vol. 3, no. 1, 1991, pp. 1-13.

50. Durbin, P. A.: AIAA J., vol. 33, no. 4, 1995, pp. 659-664.

51. Launder, B. E.; and Shima, N.: AIAA J., vol. 27, no. 10,1989 , pp. 1319-1325.

52. Lai, Y. G.; and So, R. M. C.: J. Fluid Mechanics, vol. 221, 1990, pp. 641-673.

53. So, R. M. C.; Lai, Y. G.; and Hwang, B. C.: AIAA J., vol. 29, no. 8, 1991, pp. 1202-1213.

54. Craft, T. J.; and Launder, B. E.: Turbulent Shear Flows, vol. 10, 1995, pp. 20-25-20-30.

55. Jakirlic̀,S.: and Hanjalič, K.: Turbulent Shear Flows, vol. 10, 199, pp 23-25 - 23-305.

56. Durbin, P.: J. Fluid Mech., vol. 249, 1993, pp. 465-498.

57. Huang, P. G.; Coleman, G. N.; and Bradshaw, P.: J. Fluid Mech., vol. 305, 1995, pp. 185-218.

58. Zeman, O.: Phys. Fluids A, vol. 2, no. 28, 1990, pp. 178-18.

59. Sarkar, S.; Erlebacher G.; Hussaini, M. Y.; and Kreiss, H. O.: J. Fluid Mech., vol. 227, 1989, pp. 473-493.

60. Viegas, J. R.; and Rubesin, M. W.: AIAA J., vol. 30, no. 10, 1992, pp. 2369-2379.

61. Baz, A. AM. EL; and Launder, B. E.: Engineering Turbulence Modelling and Experiments (ed., W. Rodi and F. Martelli), Elsevier, 1993.

62. Sarkar, S.; Erlebacher, G.; and Hussaini, M. Y.: Turbulent Shear Flows (ed., F. Durst et al.), Springer, 1992. 
63. Zeman, O.: AIAA 93-0897, 1993.

64. Huang, P. G.; Bradshaw, P.; and Coakley, T. J.: AIAA J., vol. 31, 1993, pp. 1600-1604.

65. Coakley, T. J.; and Huang, P. G.: AIAA 92-0436, 1992.

66. Huang, P. G.; and Coakley, T. J.: AIAA 93-0200, 1993.

67. Bardina, J. E.; Huang, P. G.; and Coakley, T. J.: to appear in a NASA TM, 1996.

68. Menter, F. R.: AIAA J., vol. 30 , no. 6, 1992 , pp. 1657-1659.

69. Huang, P. G.; Schwarz, W. R.; and Bradshaw, P.: Internal Report, Dept. of Mech. Engrg., Stanford University, June 1990.

70. Roger, S. E.; and Kwak, D.: NASA TM-103911, 1992.

71. Huang, P. G.; and Coakley, T. J.: AIAA 92-0547, 1992.

72. Driver, D. M.: AIAA 91-1787, 1991.

73. Berg, B. van den; Elsenaar, A.; Lindhout, J. P. F.; and Wesseling, P.: JFM 70, 127, 1975.

74. Bradshaw, P.; and Pontikos, N. S.: JFM, vol. 159, 1985, pp. 105-130.

75. Bachalo, W. D.; and Johnson, D. A.: AIAA J., vol. 24,1986 , pp. 437-443.

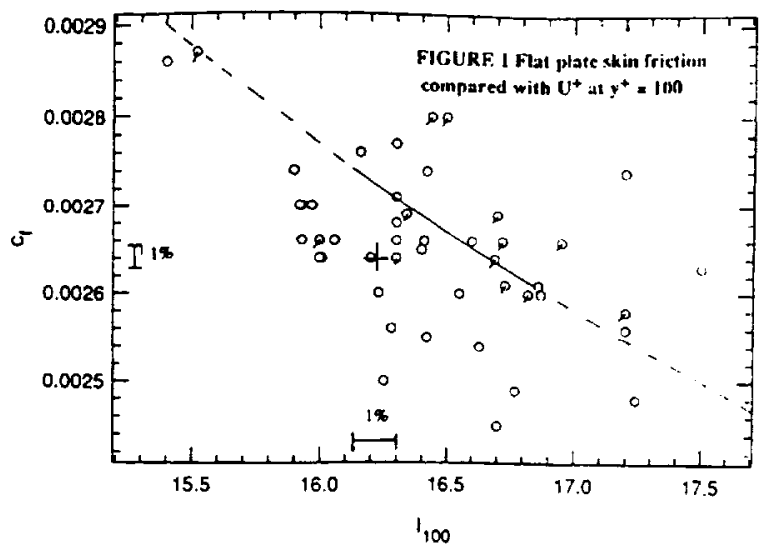

Figure 1. Flat plate skin friction compared with $U^{+}$ at $y^{+}=100$.
76. Cook, P.; Mcdonald, M.; and Firmin, M.: AGARD AR-138, 1979.

77. Bradshaw, P.: in 1980-81 AFOSR-HTTMStanford Conference on Complex Turbulent Flows, edited by S. J. Kline, B. J. Cantwell and G. M. Lilley, Stanford University, Stanford, California, vol. 1, 1981, pp. 364-368.

78. Davis, D. O.; and Gessner, F. B.: AIAA J., vol. 30 , no. 2 , 1992, pp. 367-375.

79. Johnson, P. L.; and Johnston, J. P.: Stanford Rept. MD-53, 1989.

80. Alving, A.E.; Smits, A. J.; and Watmuff, J. H.: JFM, vol. 211, 1990, pp. 529-556.

81. Driver, D. M.; and Seegmiller, H. L.: AIAA J., vol. 23 , no. 2 , 1985 , pp. 163-171.

82. Mateer, G. G.; Seegmiller, H. L.; Hand, L. A.; and Szodruch, J.: NASA TM-103933, 1992.

83. Wideman, J. K.; Brown, J. L.; Miles, J. B.; and Özcan, O.: NASA TM-108824, 1994.

84. Rogers, S. E.; Menter, F. R.; Durbin, P. A.; and Mansour, N. N.: AIAA-94-0291, 1994.

85. Kern, S. B.: AIAA-96-0057, 1996.

86. Marconi, F.; Siclari, M.; Carpenter, G.; and Chow, R.: ALAA-94-2237, 1994.
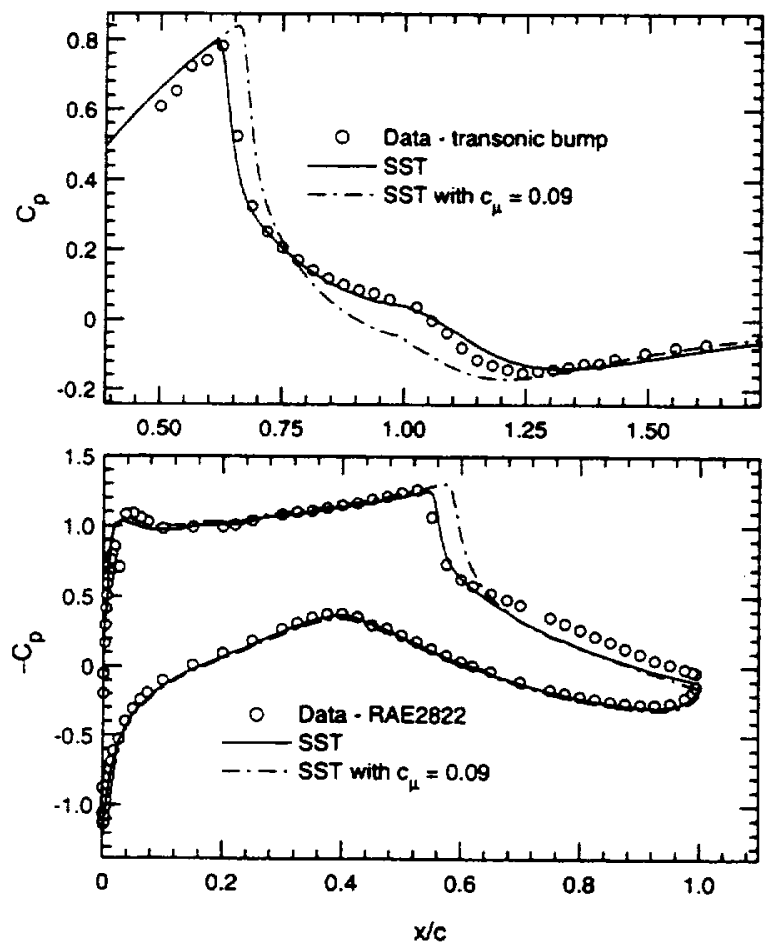

Figure 2. Pressure coefficients along the surface of (a) the transonic bump and (b) the RAE 2822 Case 10 . 


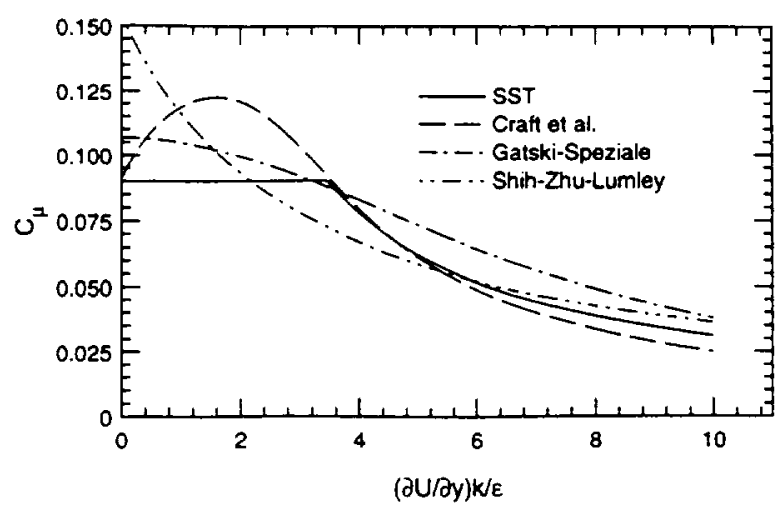

Figure 3. Variation $c_{u}$ with $S^{*}$.

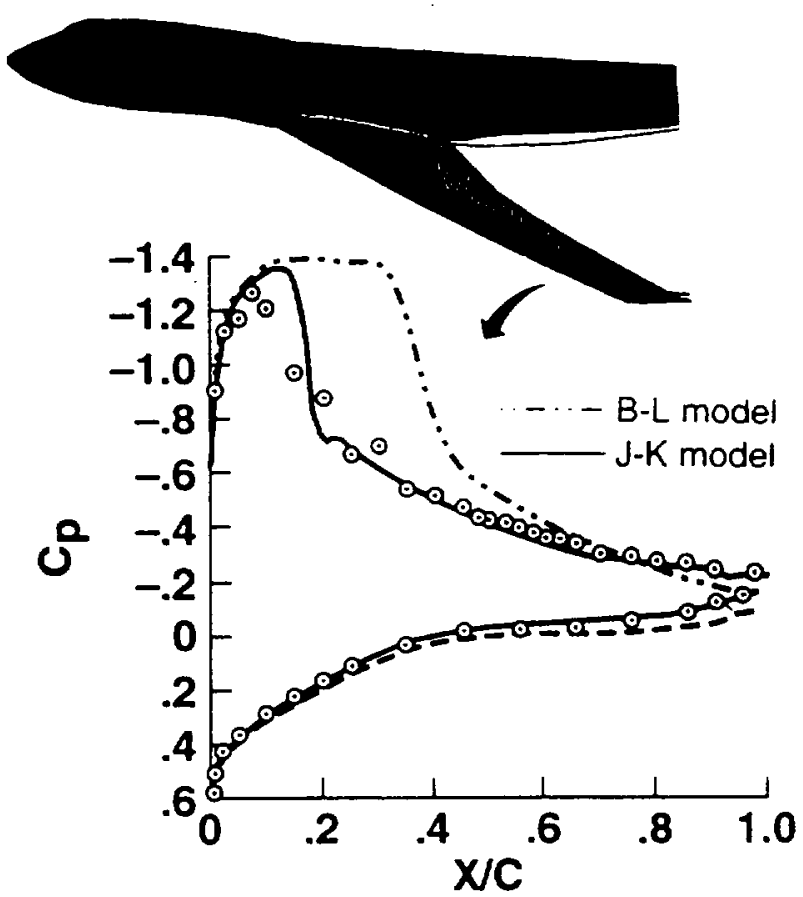

Figure 4. Improved turbulence model for a separated flow calculation of a 747-200 aircraft, $M_{\infty}=0.85$, $\alpha=5.7^{\circ}$.
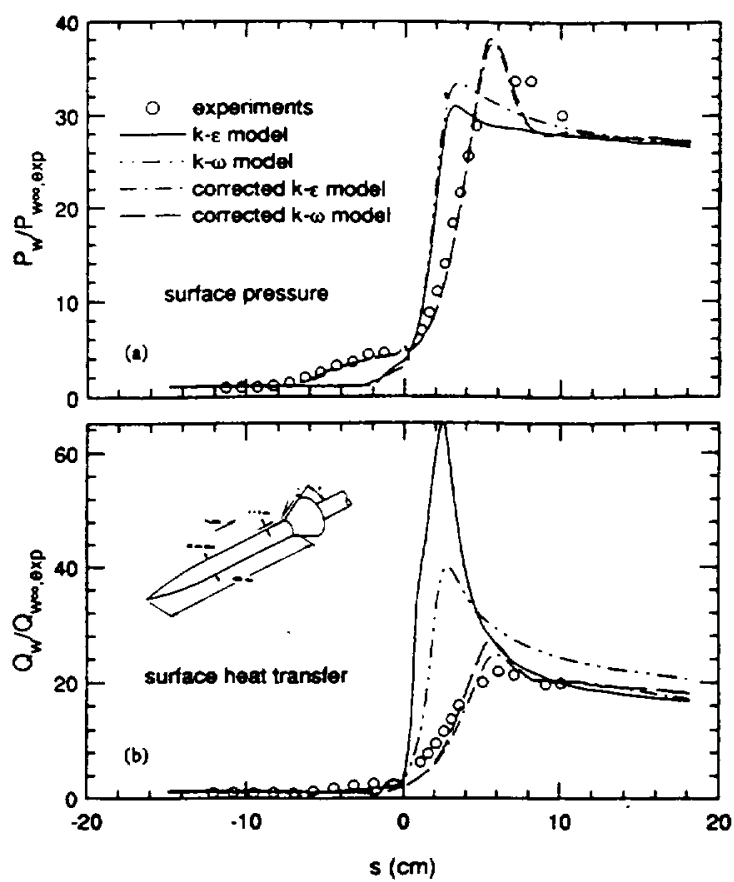

Figure 5. Compressible modification - prediction of surface pressure and heat transfer of a hypersonic flow $(M=7)$ over $35^{\circ}$ cylinder-flare.

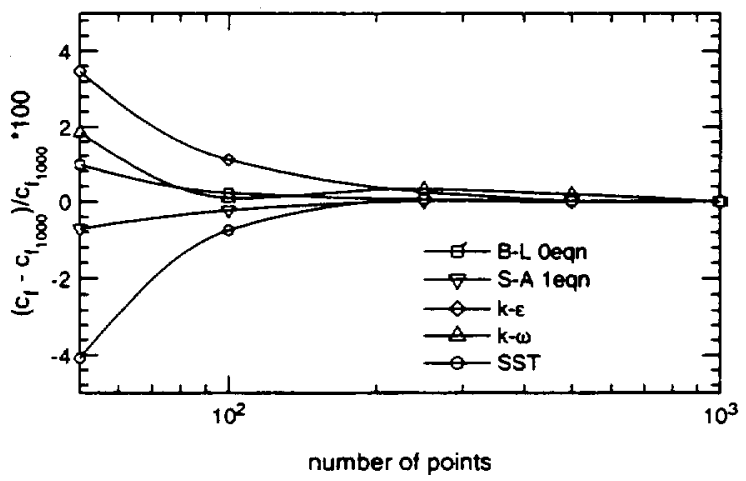

Figure 6. Sensitivity of predicted skin friction on a flat plate to grid refinement. 


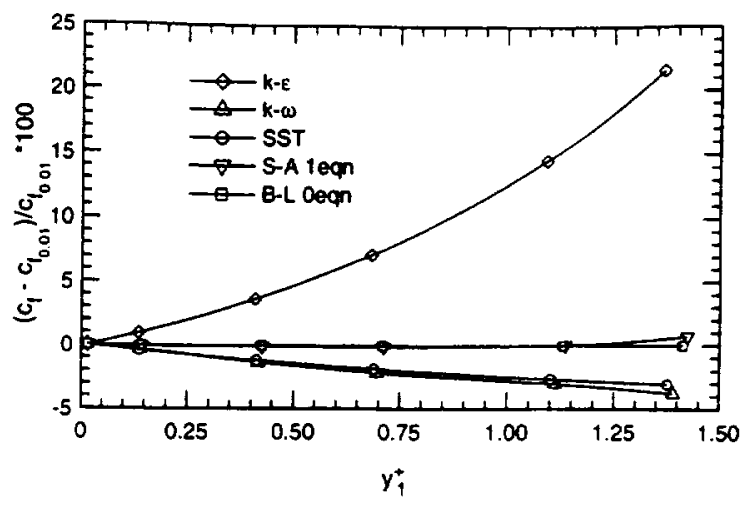

Figure 7. Sensitivity of predicted skin friction on a a flat plate to the value of $y_{1}^{+}$.

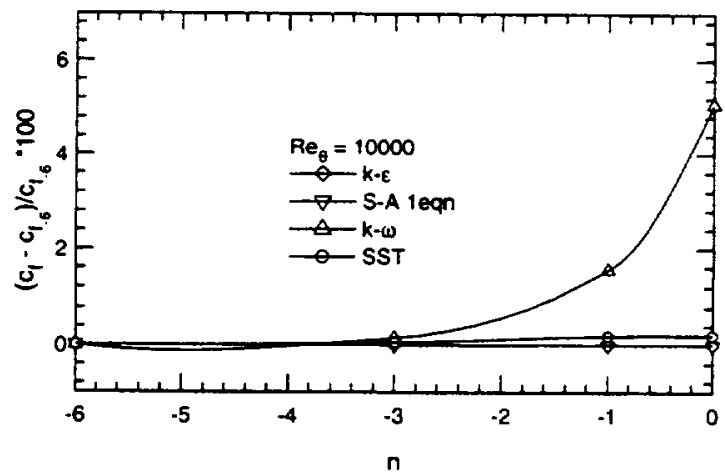

Figure 8. Sensitivity of predicted skin friction on a flat plate to free stream boundary conditions.

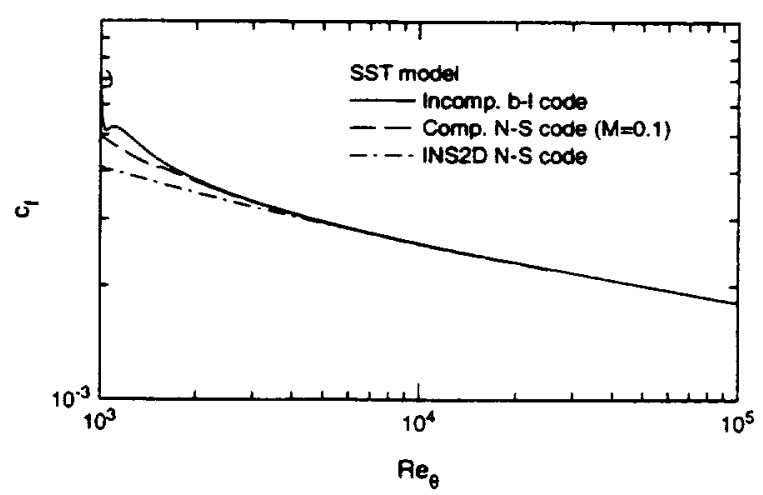

Figure 9. Code-to-code comparison of predicted skin friction on a flat plate.
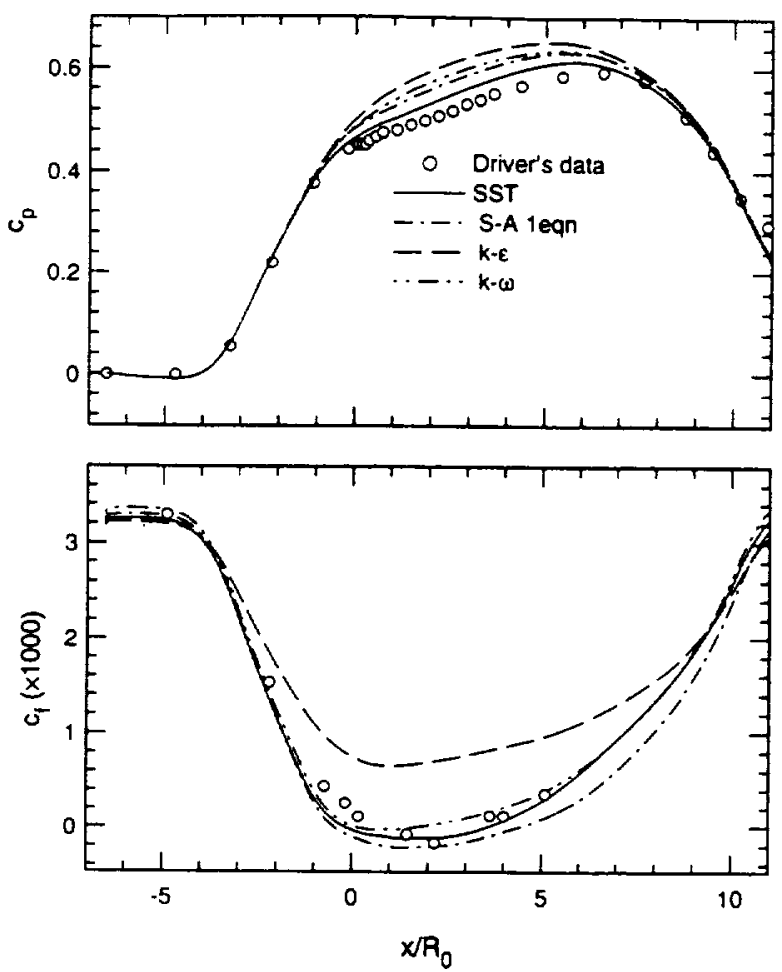

Figure 10. Comparison of surface pressure and skin friction coefficients: Driver's adverse pressure gradient flow.

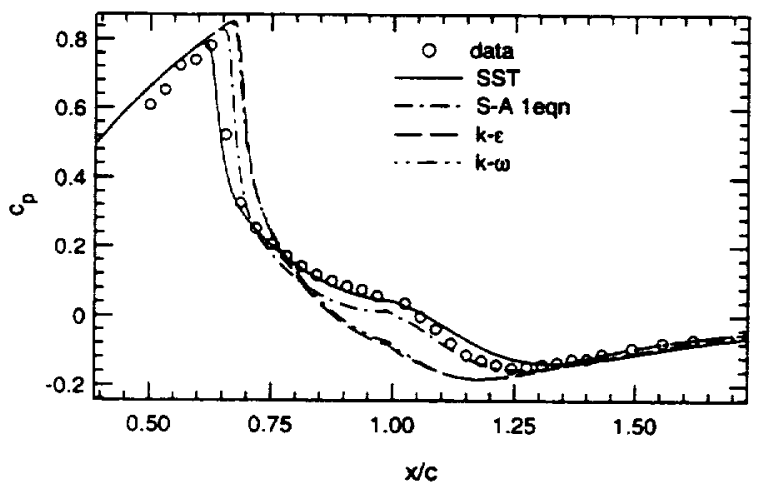

Figure 11. Comparison of surface pressure friction coefficient: Transonic bump flow: $M=0.875$ and $R e / L=13.1 \times 10^{6} / \mathrm{m}$. 

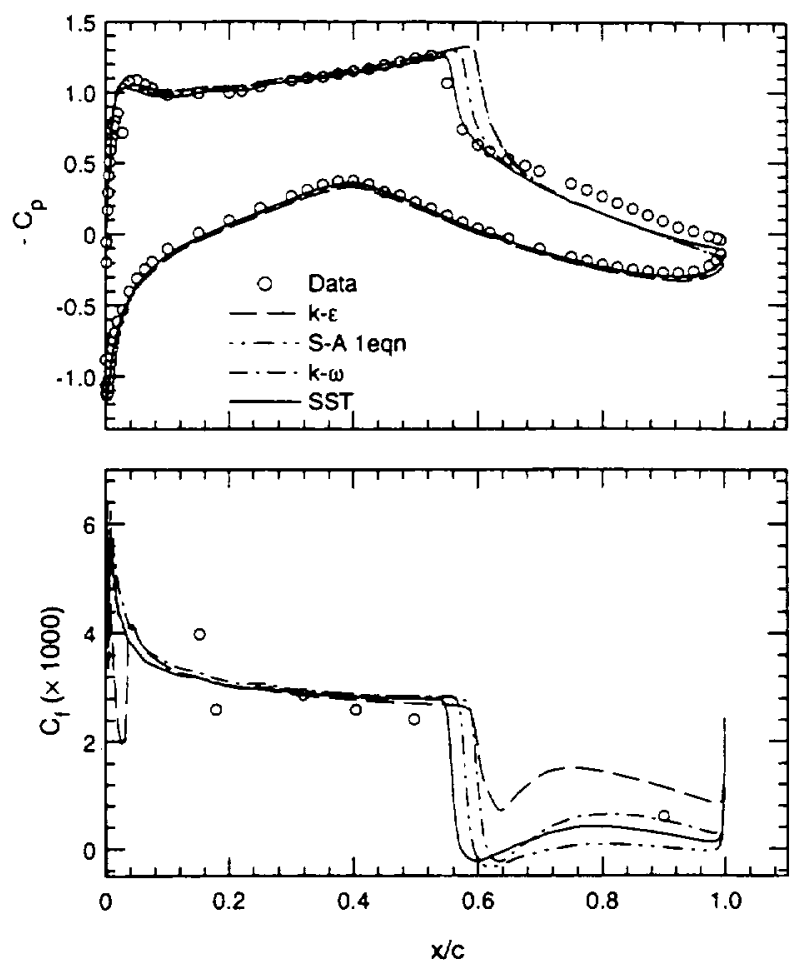

Figure 12. Comprison of surface pressure and skin friction coefficients: RAE2822, Case 10.

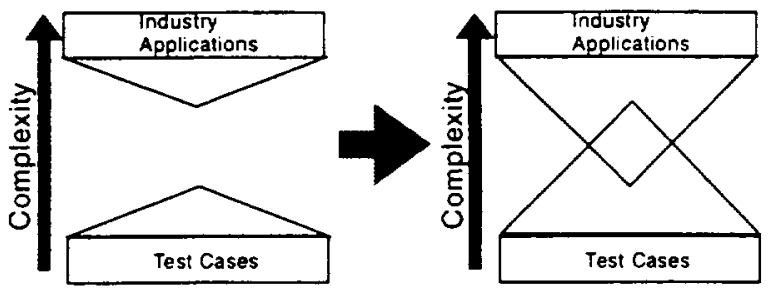

Figure 13. Old and new paradigms used in turbulence model development.

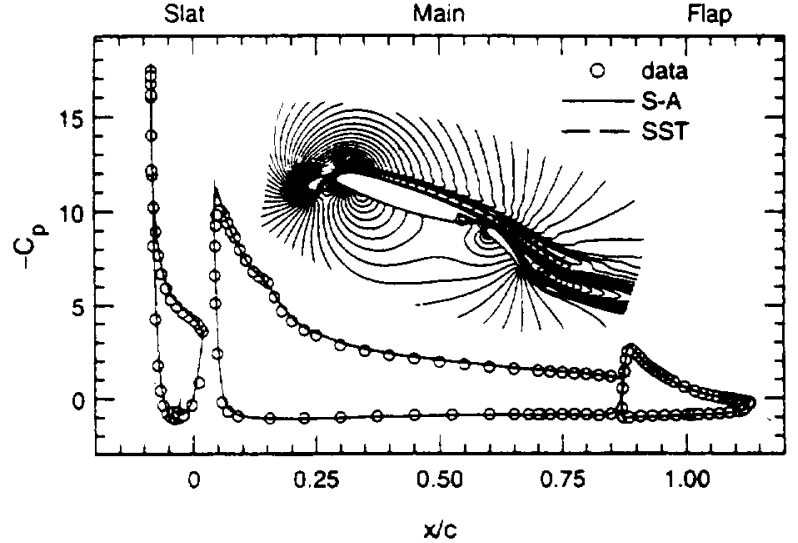

Figure 14. Prediction of surface pressure coefficient on a McDonnell-Doublas multi-element airfoil. $R e=9 \times 10^{6}$ and $\alpha=21^{\circ}$.

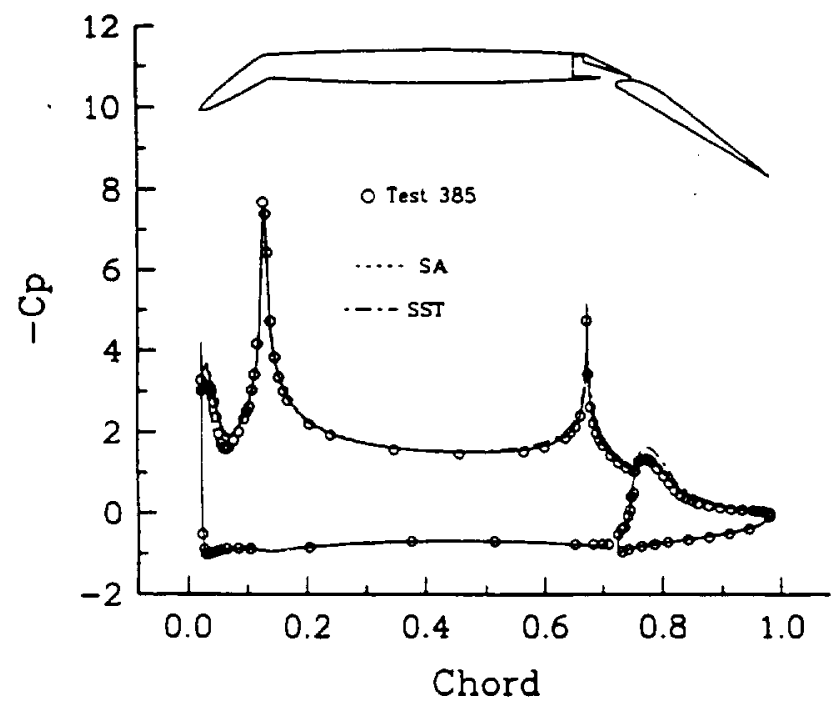

Figure 15. Prediction of surface pressure coefficient on a F/A-18E/F multi-element airfoil. $R e=12 \times 10^{6}$ and $\alpha=4^{\circ}$. 


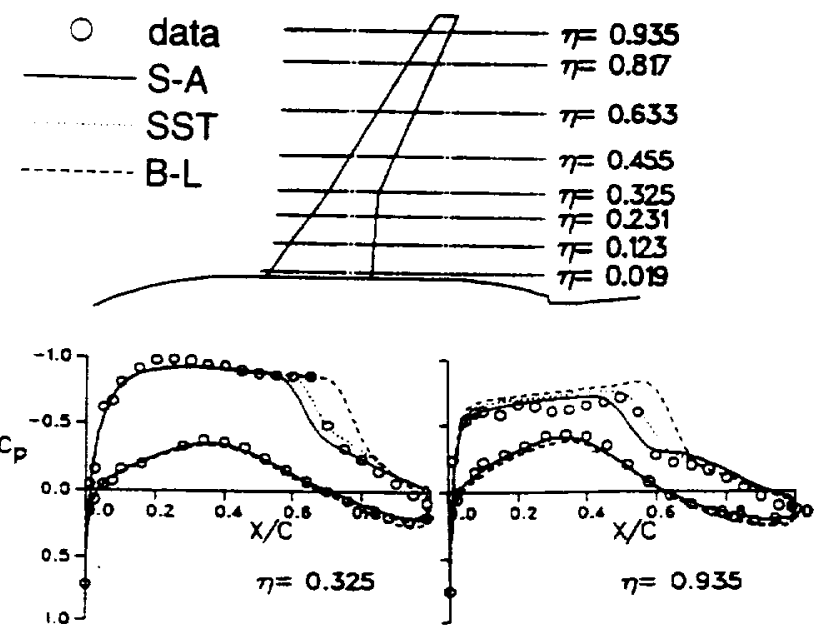

Figure 16. Prediction of surface pressure coefficient on transport wing/simple body configuration. $M_{\infty}=0.88$ and $\alpha=0.47^{\circ}$.

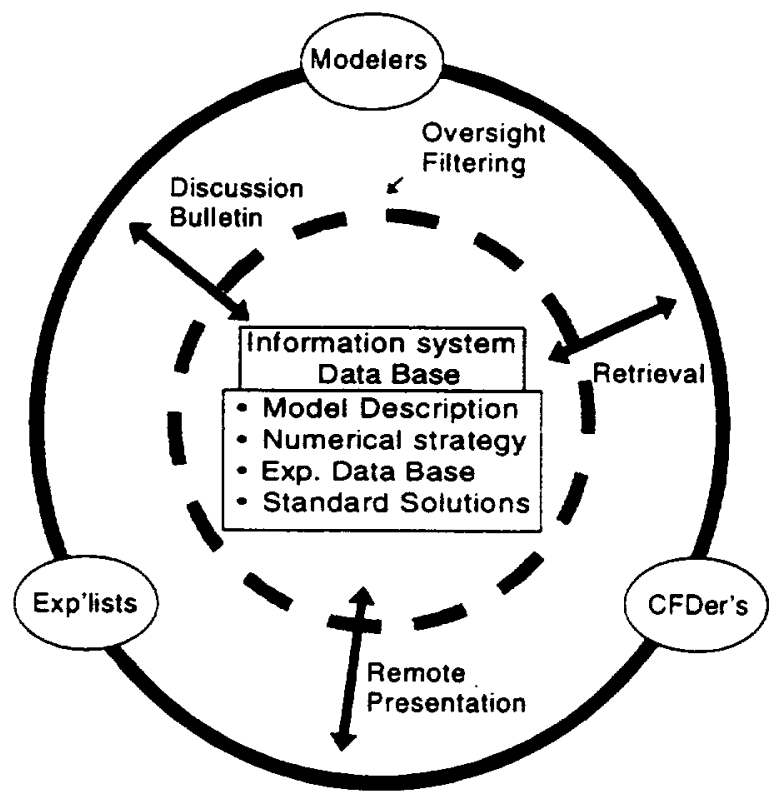

Figure 17. A conceptual information system for turbulence modeling. 

Public reporting burden for this collection of information is estimated to average 1 hour per response, including the time for reviewing instructions, searching existing data sources, gathering and maintaining the data needed, and completing and reviewing the collection of intormation. Send comments regarding this burden estimate or any other aspect of this collection of Davis Highway, Suite 1204, Arlington, VA 22202-4302, and to the Otfice of Management and Budget, Paperwork Reduction Project (0704-0188). Washington, DC 20503.

\begin{tabular}{l|l|l} 
1. AGENCY USE ONLY (Leave blank) & 2. REPORT DATE & 3. REPORT TYPE AND DATES COVERED
\end{tabular} August 1996 Technical Memorandum

4. TITLE AND SUBTITLE

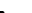
5. FUNDING NUMBERS

Turbulence Modeling - Progresss and Future Outlook

6. AUTHOR(S)

$505-59-50$

Joseph G. Marvin and George P. Huang*

7. PERFORMING ORGANIZATION NAME(S) AND ADDRESS(ES)

8. PERFORMING ORGANIZATION REPORT NUMBER

Ames Research Center

Moffett Field, CA 94035-1000

A-962417

9. SPONSORING/MONITORING AGENCY NAME(S) AND ADDRESS(ES)

10. SPONSORING/MONITORING AGENCY REPORT NUMBER

National Aeronautics and Space Administration

Washington, DC 20546-0001

NASA TM-110414

11. SUPPLEMENTARY NOTES

Point of Contact: Joseph G. Marvin, Ames Research Center, MS 200-1, Moffett Field, CA 94035-1000 (415) 604-5390

* MCAT Inc., San Jose, California

12a. DISTAIBUTION/AVAILABILITY STATEMENT

Unclassified-Unlimited

Subject Category - 34

13. ABSTRACT (Maximum 200 words)

Progress in the development of the hierarchy of turbulence models for Reynolds-averaged Navier-Stokes codes used in aerodynamic applications is reviewed. Steady progress is demonstrated, but transfer of the modeling technology has not kept pace with the development and demands of the computational fluid dynamics (CFD) tools. An examination of the process of model development leads to recommendations for a mid-course correction involving close coordination between modelers, CFD developers, and application engineers. In instances where the old process is changed and cooperation enhanced, timely transfer is realized. A turbulence modeling information database is proposed to refine the process and open it to greater participationamong modeling and CFD practitioners.

\begin{tabular}{|c|c|c|c|}
\hline \multirow{2}{*}{\multicolumn{3}{|c|}{$\begin{array}{l}\text { 14. SUBJECT TERMS } \\
\text { Computational fluid dynamics, Turbulence modeling, Experimental fluid } \\
\text { dynamics }\end{array}$}} & \multirow{2}{*}{$\begin{array}{l}\text { 15. NUMBER OF PAGES } \\
19 \\
\text { 16. PRICE CODE } \\
\text { AO3 }\end{array}$} \\
\hline & & & \\
\hline Unclassified & Unclassified & & \\
\hline
\end{tabular}

